\title{
FAKTOR-FAKTOR YANG MEMPENGARUHI KINERJA DPRK DALAM PENGAWASAN KEUANGAN DAERAH DENGAN KOMITMEN PROFESIONAL SEBAGAI VARIABEL MODERATING (STUDI EMPIRIS PADA DPRK KABUPATEN ACEH UTARA)
}

\author{
Rany Gesta Putri Rais \\ Fakultas Ekonomi dan Bisnis Universitas Malikussaleh \\ ranygesta@unimal.ac.id
}

\begin{abstract}
The objective of this research was to find out: 1) the influence of the parliamentarians' knowledge of budget, personal background, political background, public accountability, community participation, and public policy transparency on the performance of DPRK (Regency Parliament) in regional financial monitoring; 2) that professional commitment is able to become moderating variable to the relationship of the parliamentarians' knowledge on budget, personal background, political background, public accountability, community participation, and public policy transparency with the performance of DPRK in the regional financial monitoring. This research applied quantitative method. It was carried out in October 2018 at the DPRK of North Aceh Regency with term of office from 2014 to 2019. The data were collected through questionnaires distributed to 45 respondents who are members of DPRK of North Aceh Regency by using census technique. The data analysis was performed using reliability and validity tests, classic assumption test, multiple linear regression methods and residual test by means of SPSS. The result of this research showed 1) that the parliamentarians' knowledge on budget, personal background, political background, public accountability, community participation, and public policy transparency simultaneously influenced the performance of the DPRK in the regional financial monitoring, and 2) that professional commitment was not able to become the moderating variable to the relationship of the parliamentarians' knowledge on budget, personal background, political background, public accountability, community participation, and public policy transparency with the performance of DPRK in the regional financial monitoring.
\end{abstract}

Keywords: Parliamentarians' Knowledge on Budget, PersonalBackground, Political Background, Public Accountability, Community Participation, Public Policy Transparency, Professional Commitment, Performance of DPRK.

\section{PENDAHULUAN}

Dampak positif dari diterapkannya Undang-Undang tentang Otonomi Daerah yang berkaitan dengan kedudukan, fungsi dan hak-hak DPRD, diharapkan aspirasi yang berkembang di masyarakat lebih sering lagi dipertimbangkan, pemerintah untuk menciptakan good governance sebagai prasyarat dengan mengutamakan akuntabilitas dan transparansi.

Dalam Peraturan Mentri Dalam Negeri (Permendagri) No. 13 Tahun 2006 tentang Pedoman Pengelolaan Keuangan Daerah, pasal 311, menyebutkan bahwa (1) DPRD melakukan pengawasan terhadap pelaksanaan Peraturan Daerah (Perda) tentang APBD, (2) Pengawasan sebagaimana dimaksud pada ayat (1) bukan pemeriksaan tetapi pengawasan yang lebih mengarah untuk menjamin pencapaian sasaran yang telah ditetapkan dalam peraturan daerah tentang APBD. kemudian dapat diadopsi kedalam bentuk kebijakan publik. Pengaruh lainnya yang timbulakibat dari adanya otonomi daerah yaitu tuntutan kepada

Optimalisasi peran anggota DPRD sangat ditentukan oleh kemampuan para anggota dewan tersebut. Oleh karena itu salah satu upaya yang harus dilakukan oleh para anggota dewan adalah dengan meningkatkan kemampuannya tidak hanya di bidang politik, namun juga memiliki pengetahuan, kemampuan dan komitmennya mengenai penyusunan anggaran, mekanisme kerja legislatif, teknis pengawasan, konsepsi serta teknis penyelenggaraan pemerintahan, kebijakan publik dan lain-lain yang berkaitan dengan tugas dan hak-hak seorang anggota dewan.Permasalah yang timbul dalam melaksanakan pengawasan, adalah masalah yang 
bersifat eksternal misalkan tranparansi kebijakan publik, partisipasi masyarakat, dan akuntabilitas.

Fenomena yang ada pada provinsi Aceh, semenjak disahkannya Undang-Undang No. 11 Tahun 2006 tentang Pemerintahan Aceh dan Peraturan Pemerintahan mengenai Partai Lokal di Aceh pada pemilu legislatif telah merubah gambaran politik di Aceh, terhadap pemahaman peraturan dan juga pada suatu kebijakan yang akan dijalankan. Anggota dewan di DPRD provinsi Aceh, khususnya di Kabupaten Aceh Utara di dominasi oleh fraksi partai lokal.

\section{Perumusan Masalah}

Berdasarkan latar belakang yang telah diuraikan diatas, maka peneliti merumuskan masalah penelitian sebagai berikut:

1. Apakah pengetahuan anggota dewan tentang anggaran, personal background, political background, akuntabilitas publik, partisipasi masyarakat dan transparansi kebijakan publik berpengaruh signifikan secara simultan dan parsial terhadap kinerja DPRK dalam pengawasan keuangan daerah pada Kabupaten Aceh Utara?

2. Apakah komitmen profesional mempengaruhi hubungan antara pengetahuan anggota dewan tentang anggaran, personal background, political background, akuntabilitas publik, partisipasi masyarakat dan transparansi kebijakan publik terhadap kinerja DPRK dalam pengawasan keuangan daerah pada Kabupaten Aceh Utara?

\section{TELAAH LITERATUR \\ PENGEMBANGAN HIPOTESIS}

DAN

\section{Pengawasan Keuangan Daerah}

Menurut Undang-Undang No. 9 Tahun 2015 tentang Pemerintahan Daerah Pasal 154 menjelaskan bahwa DPRD kabupaten/kota mempunyai tugas dan wewenang melaksanakan pengawasan terhadap pelaksanaan Perda dan APBD kabupaten/kota. Pengawasan anggaran meliputi tahapan anggaran, dimulai dari saat perencanaan, pelaksanaan dan pertanggungjawaban. Maksud dari pengawasan anggaran merupakan proses pengawasan terhadap sesuai atau tidak sesuainya antara perencanaan anggaran dengan pelaksanaannya dalam melaksanakan pembangunan daerah.

\section{Kinerja DPRD dalam Pengawasan Keuangan Daerah}

Kinerja Dewan Perwakilan Rakyat Daerah adalah hasil kerja anggota DPRD yang dapat dicapai sesuai dengan fungsi dan tugasnyayakni sebagai perumus peraturan daerah, penyusun anggaran, dan sebagai pengawas atas pelaksanaan peraturan daerah yang dijalankan oleh Kepala Daerah. Ukuran kinerja adalah produktivitas, efektifitas, dan tanggung jawab atau responsibilitas.

\section{Pengetahuan Dewan tentang Anggaran}

Anggota Dewan akan mampu melaksanakan tugas, menggunakan hak-haknya dengan benar, menyelesaikan kewajibannya dengan baik dan mampu menempatkan diri dengan porporsional bila masing-masing anggota dewan memiliki pengetahuan yang dibutuhkan tentang konsep dan teknis dalam penyelenggaraan Pemerintah, kebijakan publik, dan lain sebagainya (Yudoyono, 2002). Untuk meningkatkan kinerja dalam pengawasan keuangan daerah, DPRD harus menguasai keseluruhan struktur dan proses anggaran. Maka dari itu, anggota DPRD harus memiliki pengetahuan dasar mengenai ekonomi dan anggaran daerah. Pengetahuananggota dewan mengenai mekanisme anggaran merupakan kemampuan yang didapat dari keikutsertaan dewan dalam pendidikan, pelatihan ataupun seminar mengenai keuangan daerah uang pernah diikuti.

\section{Personal Background}

Personal background adalah latar belakang diri seseorang yang meliputi banyak aspek, dan erat hubungannya dengan kualitas sumberdaya manusia. Perbedaan latar belakang personal diantara anggota dewan dapat memberikan pengaruh dalam pelkasnaan fungsi dn tugasnya sebagai anggota legislatif. Dalam penelitian ini variabel latar belakang personal (personal background) tersebut meliputi tingkat pendidikan yang ditempuh, bidang pendidikan, dan pekerjaan terakhir terdahulu anggota dewan.

\section{Political Background}

Political Backgroundyaitu latar belakang seseorang mengenai pengalamannya dalam dunia politik. Partai politik dan parlemen (legislatif) merupakan dua faktor utama yang memperoleh mandat dari masyarakat sipil, berperan mengorganisir keuasaan dan meraih kontrol atas Negara untuk kepentingan masyarakat (Hariyani, 2011). Political background tersebut meliputi pengalaman, jabatan di partai politik, latar belakang partai politik, dan kepentingan partai.

\section{Good Governance}

Good Governance yaitu, merupakan interaksi Negara dengan sektor swasta dan juga dengan masyarakat yang didasarkan pada beberapa karakteristik sebagai berikut: rule of 
low, partisipasi, transparansi, sikap responsif, berorientasi consensus, kesejahteraan/kebersamaan, efektif dan efesien, akuntabilitas, dan visi strategi (Karianga, 2011).

\section{Akuntabilitas Publik \\ Akuntabilitas Publik yaitukewajiban pihak yang diberikan amanah (agent) untuk memberikan, menyajikan dan melaporkan pertanggungjawaban, mengungkapkan segala aktifitasataupun kegiatan yang merupakan tanggungjawab anggota dewan kepada pemberi amanah (principal) yang berhak dan berwenang meminta pertanggungjawan tersebut (Mardiasmo, 2002).}

\section{Partisipasi Masyarakat}

Kunci sukses dari pelaksanaan otonomi daerah yaitu partisipasi masyarakat, karena dalam partisispasi berkaitan denganbagian pengawasan dan aspirasi. Maksud dari pengawasan disini mencakup pengawasan kepada pihak eksekutif lewat pihak legislatif. Peranan dewan melakukan pengawasan keuangan daerah akan dipengaruhi oleh keterlibatan masyarakat dalam advokasi anggaran (Ahmadi et.al, 2002).

\section{Transparansi Kebijakan Publik}

Transparansi yang dimaksud yaitu ketersediaan informasi yang lengkap, terpercaya, handal dan tepat waktu mengenai kebijakan publik dan proses pembentukannya. Tersedianya informasi tersebut, masyarakat dapat terlibat dan juga mengawasi sehingga kebijakan publik yang tercipta dapat memeberikan hasil yang maksimal bagi masyarakat dan menghindari terjadinya manipulasi dan kecurangan yang hanya mengunrungkan beberapa kelompok masyarakat saja secara tidak proposional (Haryani, 2011).

\section{Komitmen Profesional}

Komitmen professional yaitu tingkat loyalitas individu terhadap profesinya seperti yang dipersepsikan individu tersebut (Trisnaningsih, 2003). Dengan komitmen professional yang dimiliki oleh seorang anggota dewan dapat mempengaruhi perilaku dalam pengambilan keputusan dan tindakannya, seorang anggota dewan yang memiliki komitmen profesional yang baik akan menjadikan kepentingan publik sebagai salah satu pertimbangan dalam pengambilan keputusan dan menghindari perilaku yang dapat merusak profesionalismenya dalam setiap tindakannya.

\section{Kerangka Konseptual}

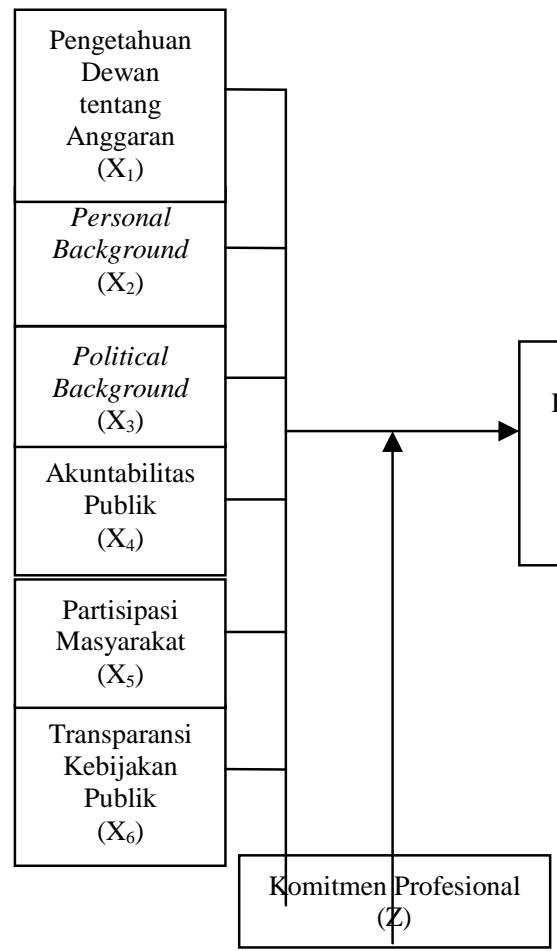

Gambar 1. Kerangka Konseptual

\section{Hipotesis Penelitian}

Hipotesis penelitian ini adalah sebagaiberikut:

$\mathrm{H}_{1}$ : Pengetahuan dewan tentang anggaran, personal background, politicalbackground, akuntabilitas publik, partisipasi masyarakat dan transparansikebijakan publik berpengaruh secara simultan dan parsial terhadap kinerja DPRK dalam pengawasan keuangan daerah pada Kabupaten Aceh Utara.

$\mathrm{H}_{2}$ : Komitmen professionalmempengaruhi hubungan antarapengetahuan dewan tentanganggaran, personal background, politicalbackground, akuntabilitas publik, partisipasi masyarakat

dantransparansikebijakanpublik terhadap kinerja DPRK dalam pengawasan keuangan daerah pada

Kabupaten Aceh Utara.

\section{METODOLOGI PENELITIAN}

Penelitian ini merupakan jenis penelitian kausal, penelitian untuk melihat hubungan antar variabel dangan variabel yang lainnya yang belum pasti. Penelitian kausal digunakan untuk menganalisis bagaimana suatu variabel berpengaruh terhadap variabel lainnya, dan juga 
dapat digunakan pada penelitian yang bersifat eksperimen yang variabel bebasnya diperlakukan dengan cara terkendali oleh peneliti untuk melihat dampaknya pada variabel terikatsecara langsung. (Umar, 2008). Penelitian dilakukanmenggunakan survey dengan pendekatan kuantitatif. Pendekatan kuantitatif dalam penelitian ini memfokuskan pada pengujian teori menggunakan variabel dengan angka dan menganalisis data menggunakan prosedur statistik.

Penelitian ini dilakukan pada lembaga DPRK Kabupaten Aceh Utara. Peneliti menetapkan populasi dalam penelitian ini yaituseluruh anggota dewan yang berada di Lembaga DPRK Aceh Utara sebanyak 45 orang. Metode sampling yang digunakanyaitu metode sensus, yang mana seluruh populasi yaitu anggota DPRK Aceh Utara berjumlah 45 orang dijadikan sampel dalam penelitian ini.

Sumber data penelitian ini adalah hal yang penting menjadi pertimbangan dalam menentukan metode pengumpulan data yang akan digunakan. Penelitian ini menggunakan data primer. Metode Pengumpulan data primer dari responden dilakukan dengan cara survei, peneliti mengumpulkan data utama (data primer) dari suatu sampel dengan menggunakan kuisioner yang terdiri dari beberapa daftar pertanyaan tertulis yang diajukan kepada responde

\section{Definisi Operasional Variabel}

Tabel 1. Definisi Operasional Variabel

\begin{tabular}{|c|c|c|c|}
\hline Variabel & Definisi Operasional & Parameter & Skala \\
\hline \multicolumn{4}{|l|}{ Dependen } \\
\hline $\begin{array}{l}\text { Kinerja DPRK } \\
\text { dalam } \\
\text { Pengawasan } \\
\text { Keuangan darah } \\
\text { (Y) }\end{array}$ & $\begin{array}{l}\text { Hasil kinerja yang } \\
\text { dilakukan DPRK dalam } \\
\text { menjalankan salah satu } \\
\text { fungsi tugasnya sebagai } \\
\text { pengawasan keuangan } \\
\text { daerah, yang mencakup } \\
\text { pengawasan saat } \\
\text { penyusunan, pengesahan } \\
\text { serta } \\
\text { pertanggungjawaban } \\
\text { anggaran (APBD). }\end{array}$ & $\begin{array}{l}\text { - Keterlibatan Anggota Dewan saat penyusunan } \\
\text { dan kebijakan umum APBD. } \\
\text { - Keterlibatan Dewan saat pengesahan APBD. } \\
\text { - Anggota Dewan mampuan menjelaskan } \\
\text { APBD yang telah disusun. } \\
\text { - Kepercayaan Dewan bahwa APBD telah } \\
\text { memenuhi kriteria transparansi. } \\
\text { - Terlibatnya Dewan dalam memonitori } \\
\text { pelaksanaan APBD. } \\
\text { - Dewan melakukan evaluasi terhadap Laporan } \\
\text { Pertanggungjawaban. } \\
\text { - Evaluasi yang dilakukan Dewan } \\
\text { terhadapfaktor-faktor atau alasan-alasan yang } \\
\text { menyebabkan terjadinya revisi APBD. } \\
\text { - Anggota Dewan meminta keterangan kepada } \\
\text { Kepala Daerahmengenai Laporan } \\
\text { Pertanggungjawaban (LPJ) APBD yang } \\
\text { disampaikannya. } \\
\text { - Penindaklanjutan dari dewan jika terjadi } \\
\text { keanehan dalam LPJ APBD. }\end{array}$ & Interval \\
\hline $\begin{array}{l}\text { Pengetahuan } \\
\text { Dewan tentang } \\
\text { Anggaran }\left(\mathrm{X}_{1}\right)\end{array}$ & $\begin{array}{l}\text { Pengetahuan dewan } \\
\text { tentang anggaran adalah } \\
\text { anggapan responden } \\
\text { mengenai anggaran } \\
\text { (RAPBD/APBD) dan } \\
\text { deteksi kegagalan, } \\
\text { pemborosan dan } \\
\text { kebocoran anggaran. }\end{array}$ & $\begin{array}{l}\text { - Pengetahuan terhadap penyusunan APBD } \\
\text { - Pengetahuan terhadap pelaksanaan APBD } \\
\text { - Pengetahuan untuk mendeteksi terjadinya } \\
\text { kebocoran dalam pelkasanaan APBD. } \\
\text { - Pengetahuan untuk mendeteksi terjadinya } \\
\text { pemborosan atau kegagalan dalam } \\
\text { pelaksanaan ABPD. }\end{array}$ & Interval \\
\hline $\begin{array}{l}\text { Personal } \\
\text { Backround }\left(\mathrm{X}_{2}\right)\end{array}$ & $\begin{array}{l}\text { Personal background } \\
\text { yaitu latar belakang } \\
\text { anggota dewan itu } \\
\text { sendiri yang meliputi } \\
\text { tingkat pendidikan yang } \\
\text { ditempuh, bidang } \\
\text { pendidikan serta }\end{array}$ & $\begin{array}{l}\text { - Tingkat Pendidikan } \\
\text { - Bidang Pendidikan } \\
\text { - Pekerjaan sebelum menjadi anggota dewan }\end{array}$ & Interval \\
\hline
\end{tabular}


pekerjaannya sebelum menjadi anggota dewan.

\begin{tabular}{|c|c|c|c|}
\hline $\begin{array}{l}\text { Political } \\
\text { Background } \\
\left(\mathrm{X}_{3}\right)\end{array}$ & $\begin{array}{l}\text { Political background } \\
\text { yaitu merupakan latar } \\
\text { belakang dari } \\
\text { pengalaman anggota } \\
\text { dewan dalam dunia } \\
\text { politik }\end{array}$ & $\begin{array}{l}\text { - Pengalaman di partai politik } \\
\text { - Jabatan di partai politik } \\
\text { - Latar belakang partai politik } \\
\text { - Sejauhnya mana kepentingan partai lebih } \\
\text { diutamakna oleh anggota DPRK. }\end{array}$ & Interval \\
\hline $\begin{array}{l}\text { Akuntabilitas } \\
\text { Publik }\left(\mathrm{X}_{4}\right)\end{array}$ & $\begin{array}{l}\text { Kewajiban untuk } \\
\text { menyerahkan } \\
\text { pertanggungjawaban, } \\
\text { menyajikan, melapor dan } \\
\text { mengungkapkan seluruh } \\
\text { aktivitas ataupun } \\
\text { kegiatan yang } \\
\text { merupakan } \\
\text { tanggungjawab terhadap } \\
\text { publik ataupun } \\
\text { masyarakat luas. }\end{array}$ & $\begin{array}{l}\text { - Mampu menyajikan informasi penyelengaraan } \\
\text { secara, cepat, terbuka dan tepat kepada } \\
\text { masyarakat. } \\
\text { - Dapat memberikan pelayanan yang baik bagi } \\
\text { publik. } \\
\text { - Bisa memberikan kesempatan kepada } \\
\text { masyarakat untuk ikut andil dalam proses } \\
\text { pembangunan dan pemerintahan. } \\
\text { - Mampu mempertanggungjawabkan dan } \\
\text { menjelaskan semua kebijakan publik dengan } \\
\text { proporsional. } \\
\text { - Tersedianyafasilitasuntuk publik yang dapat } \\
\text { digunakan untuk menilai kinerja pemerintah. }\end{array}$ & Interval \\
\hline $\begin{array}{l}\text { Partisipasi } \\
\text { Masyarakat } \\
\left(\mathrm{X}_{5}\right)\end{array}$ & $\begin{array}{l}\text { Partisipasi masyarakat } \\
\text { adalah keikutsertaan } \\
\text { masyarakat dalam } \\
\text { tahapan pengambilan } \\
\text { keputusan. Keterlibatan } \\
\text { masyarakat pada setiap } \\
\text { diskusi/forum dalam } \\
\text { proses mengambil } \\
\text { keputusan yang berkaitan } \\
\text { dengan kepentingan } \\
\text { bersama. }\end{array}$ & $\begin{array}{l}\text { - Pelibatan Masyarakat untuk membantu } \\
\text { Dewan dalam menjalankan fungsi tugas } \\
\text { sebagai pengawas keuangan daerah. } \\
\text { - Kritik ataupun saran masyarakat selalu } \\
\text { dijadikan masukan dalam melakukan } \\
\text { pengawasan. } \\
\text { - Masyarakat dilibatkan pada saat konsultasi } \\
\text { dan konfirmasi dengan Dewan dan } \\
\text { Pemerintah daerah tentang rancangan APBD. } \\
\text { - Terlibatnya masyarakat pada saat penyusunan } \\
\text { APBD. }\end{array}$ & Interval \\
\hline $\begin{array}{l}\text { Transparansi } \\
\text { kebijakan } \\
\text { Publik }\left(\mathrm{X}_{6}\right)\end{array}$ & $\begin{array}{l}\text { Keterbukaan informasi } \\
\text { berkaitan dengan } \\
\text { anggaran yang akurat, } \\
\text { tepatwaktu dan cukup } \\
\text { tentang kebijakan dan } \\
\text { pengelolaan anggaran } \\
\text { yang mudah diakses oleh } \\
\text { masyarakat. }\end{array}$ & $\begin{array}{l}\text { - Pengumuman atau pemberian informasi oleh } \\
\text { Pemerintah daerah tentang kebijakan } \\
\text { anggaran yang telah disusun. } \\
\text { - Kemudahan dokumen-dokumen kebijakan } \\
\text { anggaran yang telah disusun Pemerintah } \\
\text { daerah agar mudah di ketahui publik. } \\
\text { - Kemampuan transparansi anggaran dalam } \\
\text { meningkatkan dan mengakomodasi usulan } \\
\text { masyarakat. } \\
\text { - Penyampaian laporan pertanggungjawaban } \\
\text { yang tepat waktu. }\end{array}$ & Interval \\
\hline $\begin{array}{l}\text { Komitmen } \\
\text { Profesional (Z) }\end{array}$ & $\begin{array}{l}\text { Komitmen responden } \\
\text { sebagai wakil rakyat } \\
\text { bukan wakil sekelompok } \\
\text { orang/ golongan untuk } \\
\text { melakukan pengawasan } \\
\text { yang optimal dalam } \\
\text { melaksanakan } \\
\text { pengawasan keuangan } \\
\text { daerah. }\end{array}$ & $\begin{array}{l}\text { - Komitmen bahwa anggota legislatif adalah } \\
\text { wakil rakyat. } \\
\text { - Komitmen dalam pemahaman etika dan sikap } \\
\text { ketaatan terhadap aturan perundang- } \\
\text { undangan. } \\
\text { - Komitmen bahwa anggota legislatif } \\
\text { mempunyai tanggung jawab untuk menjaga } \\
\text { kredibilitas Lembaga. } \\
\text { - Dewan harus selalu bersikap netral dalam } \\
\text { mempertimbangkan usulan/kebutuhan } \\
\text { masyarakat, tanpa melihat apakah mendukung }\end{array}$ & Interval \\
\hline
\end{tabular}


partainya ataukah pendukung partai lain.

\section{Model Penelitian}

Model analisis data yang digunakan untuk menguji hipotesis pertama adalah regresi liner berganda dan hipotesis kedua dengan menggunakan uji residual. Berdasarkan hipotesis yang yang diajukan, maka model penelitian ini adalah:

Model I : $Y=a+b_{1} X_{1}+b_{2} X_{2}+b_{3} X_{3}+b_{4} X_{4}$ $+b_{5} X_{5}+b_{6} X_{6+} e$

Model II : $Z=a+b_{1} X_{1}+b_{2} X_{2}+b_{3} X_{3}+b_{4}$ $|\mathrm{e}|=\mathrm{a}+\mathrm{b}_{1} \mathrm{Y}$

Keterangan:

Y = Kinerja DPRK dalam

pengawasan keuangan daerah

a $\quad=$ Konstanta

$\mathrm{X}_{1} \quad=$ Pengetahuan Dewan tentang

Anggaran

$\mathrm{X}_{2} \quad=$ Personal Background

$\mathrm{X}_{3} \quad=$ Political Background

$\mathrm{X}_{4} \quad=$ Akuntabilitas Publik

$\mathrm{X}_{5} \quad=$ Partisipasi Masyarakat

$\mathrm{X}_{6} \quad=$ Transparansi Kebijakan Publik

$\mathrm{Z} \quad=$ Komitmen Profesional

$\mathrm{b}_{1}-\mathrm{b}_{6}=$ Koefesien regresi

$\mathrm{e}=$ Error

\section{HASIL DAN PEMBAHASAN}

Tabel 2. Statistik Deskriptif

\section{Descriptive Statistics}

\begin{tabular}{l|r|r|r|r|r}
\hline & \multicolumn{1}{|c|}{$\mathrm{N}$} & Min & Max & Mean & Std. Dev \\
\hline $\mathrm{X}_{1}$ & 45 & 16 & 20 & 17.78 & 1.277 \\
\hline $\mathrm{X}_{2}$ & 45 & 9 & 15 & 11.38 & 1.787 \\
\hline $\mathrm{X}_{3}$ & 45 & 12 & 24 & 18.62 & 3.214 \\
\hline $\mathrm{X}_{4}$ & 45 & 19 & 24 & 20.98 & 1.252 \\
\hline $\mathrm{X}_{5}$ & 45 & 15 & 20 & 17.69 & 1.635 \\
\hline $\mathrm{X} 6$ & 45 & 16 & 20 & 18.42 & 1.602 \\
\hline $\mathrm{Z}$ & 45 & 16 & 20 & 17.47 & 1.140 \\
\hline $\mathrm{Y}$ & 45 & 36 & 41 & 38.93 & 1.671 \\
\hline Valid & 45 & & & & \\
$\mathrm{~N}$ & & & & & \\
\hline
\end{tabular}

Sumber: Hasil Penelitian, 2018

\section{Pengujian Asumsi Klasik}

Uji Asumsi klasik ini menggunakan Uji normalitas, multikolinearitas,

dan heterokedastisitas. Hasil uji normalitas, multikolinearitas, dan heterokedastisitas menunjukkan data terdistribusi normal, tidak mengalami multikolinearitas, dan bebas dari heterokedastisitas (homokedastisitas) antar variabel.

\section{Hasil Uji Hipotesis}

Pengujian yang digunakan dalam penelitian ini yaitu koefesien determinasi $\left(\mathrm{R}^{2}\right)$, Uji F, uji t dan uji residual (pemoderasi).

\section{Koefesien Determinasi $\left(\mathbf{R}^{2}\right)$}

Koefesien determinasi bisa menjelaskan variabel terikat apabila Adjusted $R^{2}>5 \%$. Dalam penelitian ini koefesien Adjusted $R^{2}$ sebesar $0,941(94,1 \%)$ berarti $94,1 \%$ variasi variabel terikat pada model diterangkan oleh variabel bebas, sedangkan sisanya sebesar 5,9\% dapat dijelaskan oleh variabel lain diluar model.

Tabel 3. Koefesien Determinasi $\left(\mathbf{R}^{2}\right)$

\begin{tabular}{|c|c|c|c|c|}
\hline Model & $\mathrm{R}$ & $\mathrm{R}^{2}$ & $\begin{array}{l}\text { Adjusted } \\
\qquad \mathrm{R}^{2}\end{array}$ & $\begin{array}{l}\text { Std. Error } \\
\text { of the } \\
\text { Estimate }\end{array}$ \\
\hline 1 & $.974^{\mathrm{a}}$ & .949 & .941 & .405 \\
\hline
\end{tabular}

Sumber: Hasil Penelitian 2018

\section{Hasil Hipotesis Pertama}

1. Uji F

Uji F ini bertujuan mengetahui pengaruh secara serentakantara variabel independen dengan variabel dependen dalam penelitian.

Tabel 4. Hasil Uji F

\begin{tabular}{|c|c|c|c|c|c|}
\hline \multicolumn{6}{|c|}{ ANOVA $^{b}$} \\
\hline Model & $\begin{array}{c}\text { Sum } \\
\text { of } \\
\text { Square } \\
\text { s }\end{array}$ & df & $\begin{array}{l}\text { Mean } \\
\text { Square }\end{array}$ & $\mathrm{F}$ & Sig. \\
\hline $\begin{array}{l}\text { Regressi } \\
\text { on }\end{array}$ & $\begin{array}{r}116.57 \\
8\end{array}$ & 6 & 19.430 & $\begin{array}{r}118.65 \\
8\end{array}$ & $.000^{\mathrm{a}}$ \\
\hline Residual & 6.222 & 38 & .164 & & \\
\hline Total & $\begin{array}{r}122.80 \\
0\end{array}$ & 44 & & & \\
\hline
\end{tabular}

Sumber: Hasil Penelitian, 2018

Berdasarkan tabel diketahui nilai signifikan 0,000 lebih kecil dari 0,05, maka $\left(\mathrm{H}_{0}\right.$ ditolak), artinya semua variabel independen yaitu: pengetahuan dewan tentang anggaran, personal background, Political background, akuntabilitas publik, partisipasi masyarakat, transparansi kebijakan publicsecara simultan berpengaruh terhadap variabel dependen yaitu kinerja DPRK dalam pengawasan keuangan daerah pada taraf signifikansi $\alpha=5 \%$. 


\section{Uji t}

Uji t ini bertujuan mengetahui pengaruh secara parsial antara variabel independen dengan variabel dependen penelitian.

Tabel 5. Hasil Uji t

\begin{tabular}{|c|c|c|c|c|c|}
\hline \multirow[t]{2}{*}{ Model } & \multicolumn{2}{|c|}{$\begin{array}{c}\text { Unstand. } \\
\text { Coefficients }\end{array}$} & \multirow{2}{*}{\begin{tabular}{|c}
$\begin{array}{c}\text { Stand. } \\
\text { Coefficien } \\
\text { ts }\end{array}$ \\
\\
Beta
\end{tabular}} & \multirow[b]{2}{*}{$\mathrm{t}$} & \multirow[b]{2}{*}{ Sig } \\
\hline & B & $\begin{array}{l}\text { Std. } \\
\text { Error }\end{array}$ & & & \\
\hline (Constan & 15.7 & 1.21 & & 12.9 & .00 \\
\hline t) & 53 & 8 & & 30 & 0 \\
\hline $\mathrm{X}_{1}$ & .254 & .094 & .195 & $\begin{array}{r}2.69 \\
3\end{array}$ & $\begin{array}{r}.01 \\
0\end{array}$ \\
\hline $\mathrm{X}_{2}$ & -.036 & .042 & -.038 & -.849 & .40 \\
\hline$\overline{X_{3}}$ &.- .009 & .022 & -.018 & -.413 & .68 \\
\hline $\mathrm{X}_{4}$ & .456 & .095 & .341 & $\begin{array}{r}4.80 \\
2 \\
\end{array}$ & $\begin{array}{r}.00 \\
0 \\
\end{array}$ \\
\hline$\overline{X_{5}}$ & .420 & .075 & .411 & $\begin{array}{r}5.60 \\
0\end{array}$ & .00 \\
\hline$\overline{X_{6}}$ & .122 & .058 & .117 & $\begin{array}{r}2.12 \\
0\end{array}$ & .04 \\
\hline
\end{tabular}

Sumber: Hasil Penelitian, 2018

Berdasarkan tabel menunjukkan bahwa variabel independen pengetahuan dewan tentang anggaran, akuntabilitas publik, partisipasi masyarakat, dan transparansi kebijakan publik yang mempunyai $\mathrm{P}$ value (sig) lebih kecil dari 0,05 dalam nilai absolute pada taraf signifikan $\alpha=$ $5 \%$, dengan rincian variabel pengetahuan dewan tentang anggaran sebesar $0,010<0,05$, artinya variabel pengetahuan dewan tentang anggaran berpengaruh signifikan terhadap kinerja DPRK dalam pengawasan keuangan daerah $\left(\mathrm{H}_{0}\right.$ ditolak). Selanjutnya rincian variabel akuntabilitas publik sebesar $0,00<0,05$, artinya variabel akuntabilitas publik berpengaruh signifikan terhadap kinerja DPRK dalam pengawasan keuangan daerah $\left(\mathrm{H}_{0}\right.$ ditolak). Rincian variabel partisipasi masyarakat sebesar $0,00<0,05$, artinya variabel partisipasi masyarakat berpengaruh signifikan terhadap kinerja DPRK dalam pengawasan keuangan daerah $\left(\mathrm{H}_{0}\right.$ ditolak $)$, dan rincian variabel transparansi kebijakan publik sebesar 0,041<0,5, artinya variabel transparansi kebijakan publik berpegaruh signifikan terhadap kinerja DPRK dalam pengawasan keuangan daerah $\left(\mathrm{H}_{0}\right.$ ditolak). Sedangkan variabel personal background dan political background mempunyai nilai $\mathrm{P}$ value (sig) lebih besar dari pada 0,05 dalam nilai absolute pada taraf signifikan $\alpha=5 \%$, dengan rincian variabel personal background sebesar $0,401>0,05$, artinya variabel personal background tidak berpengaruh signifikan terhadap kinerja DPRK dalam pengawasan keuangan daerah $\left(\mathrm{H}_{0}\right.$ diterima $)$. Selanjutnya rincian variabel political backround sebesar 0,682 $>0,05$, artinya variabel political background tidak berpengaruh signifikan terhadap kinerja DPRK dalam pengawasan keuangan daerah $\left(\mathrm{H}_{0}\right.$ diterima $)$. Dari nilai-nilai koefesien tersebut, maka dapat disusun persamaan regresi sebagai berikut:

$\mathrm{Y}=15,753+0,254 \mathrm{X}_{1}-0,036 \mathrm{X}_{2}$

$$
-0,009 X_{3}+0,456 X_{4}+0,420 X_{5}+0,122 X_{6}
$$

Berdasarkan persamaan regresitersebut dapat dijelaskan sebagai berikut:

a. Pengetahuan dewan tentang anggaran $\left(X_{1}\right)$

Pengetahuan dewan tentang anggaran berpengaruh positif dan signfikan terhadap kinerja DPRK dalam pengawasan keuangan daerah dengan nilai sebesar 0,254. Pengaruh positif menunjukkan bahwa pengetahuan dewan tentang anggaran yang tinggi membuat kinerja DPRK dalam pengawasan keuangan daerah semakin baik/tinggi. Begitu pula sebaliknya, bila pengetahuan dewan tentang anggaran yang rendah membuat kinerja DPRK dalam pengawasan keuangan daerah yang buruk/rendah.

b. Personal background $\left(\mathrm{X}_{2}\right)$

Personal background memiliki pengaruh yangnegatif dan tidak signifikan terhadap kinerja DPRK dalam pengawasan keuangan daerah yang memiliki nilai sebesar -0,036. Tidak berpengaruhnya variabel personal background dalam penelitian inikarena pada DPRK Aceh Utara periode 2014-2019 di dominasi oleh anggota dewan yang meimiliki tingkat pendidikan SLTA dan bidang pendidikan diluar bidang ekonomi ataupun bidang yang berkaitan dengan fungsi, tanggungjawab serta tugas sebagai anggota dewan. Hal tersebut juga merupakan penyebab variabel personal background bernilai koefisien negatif. 
c. Political background $\left(\mathrm{X}_{3}\right)$

Political background memiliki pengaruh pengaruh negatif dan tidak signifikan terhadap variabel bebas kinerja DPRK dalam pengawasan keuangan daerah yang memiliki nilai sebesar -0,009. Tidak berpengaruhnya variabel political background dalam penelitian karena pada DPRK Aceh Utara periode 2014-2019 di dominasi oleh anggota dewan yang merupakan kader-kader baru di partai politik masing-masing dan belum pernah menjadi anggota dewan pada periode sebelumnya. Hal tersebut juga yang menyababkan variabel political background bernilai koefisien negatif.

d. Akuntabilitas Publik $\left(\mathrm{X}_{4}\right)$

Akuntabilitas public memiliki pengaruh positif dan signifikan terhadap kinerja DPRK dalam pengawasan keuangan daerah yang memiliki nilai sebesar 0,456. Pengaruh positif menunjukkan bahwa akuntabilitas publik yang tinggi membuat kinerja DPRK dalam pengawasan keuangan daerah semakin baik/tinggi. Begitu pula sebaliknya, bila akuntabilitas publik yang rendah membuat kinerja DPRK dalam pengawasan keuangan daerah yang buruk/rendah.

e. Partisipasi Masyarakat $\left(\mathrm{X}_{5}\right)$

Partisipasi masyarakat memiliki pengaruh positif dan signifikan terhadap kinerja DPRK dalam pengawasan keuangan daerah yang memiliki nilai sebesar 0,420. Pengaruh positif menunjukkan bahwa partisipasi masyarakat yang tinggi membuat kinerja DPRK dalam pengawasan keuangan daerah semakin baik/tinggi. Begitu pula sebaliknya, bila partisipasi masyarakat yang rendah membuat kinerja DPRK dalam pengawasan keuangan daerah menjadi buruk/rendah.

f. Transparansi kebijakan publik $\left(\mathrm{X}_{6}\right)$

Transparansi kebijakan publik memiliki pengaruh positif dan signifikan terhadap kinerja DPRK dalam pengawasan keuangan daerah yang memiliki nilai sebesar 0,122. Pengaruh positif menunjukkan bahwa semakin tinggi transparansi kebijakan publik maka semakin tinggi juga kinerja DPRK dalam pengawasan keuangan daerah. Begitu pula sebaliknya, bila transparansi kebijakan publik semakin rendah membuat kinerja DPRK dalam pengawasan keuangan daerah menjadi buruk/rendah.

\section{Hasil Hipotesis Kedua}

Pengujian Hipotesis kedua yaitu menganalisis apakah komitmen professional dapat menjadi variabel pemoderasi yang memperkuat atau memperlemah pengaruh pengetahuan dewan tentang anggaran, personal background, poltical background, akuntabilitas publik, partisipasi masyarakat, dan transparansi kebijakan publik terhadap kinerja DPRK dalam pengawasan keuangan daerah dengan menggunakan uji residual.

Tabel 6. Uji Residual (Pemoderasi) - Z

\begin{tabular}{|c|c|c|c|c|c|}
\hline \multicolumn{6}{|c|}{ Coefficients $^{\mathrm{a}}$} \\
\hline Model & \multicolumn{2}{|c|}{$\begin{array}{c}\text { Unstd. } \\
\text { Coefficients }\end{array}$} & \multirow{2}{*}{$\begin{array}{c}\text { Std. } \\
\text { Coefficien } \\
\text { ts } \\
\text { Beta } \\
\end{array}$} & \multirow[b]{2}{*}{$\mathrm{T}$} & \multirow[b]{2}{*}{ Sig } \\
\hline & $\mathrm{B}$ & $\begin{array}{l}\text { Std. } \\
\text { Error }\end{array}$ & & & \\
\hline (Constan & 13.9 & 3.37 & & 4.15 & .00 \\
\hline t) & 98 & 3 & & 0 & 0 \\
\hline $\mathrm{X}_{1}$ & -.104 & .262 & -.113 & -.397 & $\begin{array}{r}.69 \\
4\end{array}$ \\
\hline $\mathrm{X}_{2}$ & .019 & .116 & .028 & .160 & $\begin{array}{r}.87 \\
3 \\
\end{array}$ \\
\hline$X_{3}$ & -.085 & .061 & -.231 & $\begin{array}{r}- \\
1.37 \\
8 \\
\end{array}$ & $\begin{array}{r}.17 \\
6\end{array}$ \\
\hline $\mathrm{X}_{4}$ & -.054 & .263 & -.057 & -.204 & $\begin{array}{r}.83 \\
9 \\
\end{array}$ \\
\hline $\mathrm{X}_{5}$ & .274 & .208 & .380 & $\begin{array}{r}1.32 \\
0 \\
\end{array}$ & $\begin{array}{r}.19 \\
5 \\
\end{array}$ \\
\hline $\mathrm{X}_{6}$ & .165 & .159 & .225 & $\begin{array}{r}1.03 \\
7 \\
\end{array}$ & $\begin{array}{r}.30 \\
6 \\
\end{array}$ \\
\hline
\end{tabular}

Sumber: Hasil Penelitian, 2018 
Tabel 7. Uji Residual (Pemoderasi) $|\mathbf{e}|$

\begin{tabular}{|c|c|c|c|c|c|}
\hline \multicolumn{6}{|c|}{ Coefficients $^{\mathbf{a}}$} \\
\hline \multirow[t]{2}{*}{ Model } & \multicolumn{2}{|c|}{$\begin{array}{c}\text { Unstd. } \\
\text { Coefficients }\end{array}$} & \multirow{2}{*}{$\begin{array}{c}\text { Std. } \\
\text { Coefficien } \\
\text { ts } \\
\text { Beta }\end{array}$} & \multirow[b]{2}{*}{$\mathrm{T}$} & \multirow[b]{2}{*}{ Sig } \\
\hline & B & $\begin{array}{l}\text { Std. } \\
\text { Error }\end{array}$ & & & \\
\hline (Constan & 2.23 & 2.44 & & .914 & .36 \\
\hline t) & 4 & 4 & & & 6 \\
\hline $\mathrm{Y}$ & -.038 & .063 & -.091 & -.599 & $\begin{array}{r}.55 \\
2\end{array}$ \\
\hline
\end{tabular}

Sumber: Hasil Penelitian, 2018

Berdasarkan tabel diatas, persamaan pada model uji residual adalah sebagai berikut:

$$
\begin{aligned}
& \mathrm{Z}=13,998-0,104 \mathrm{X}_{1}+0,019 \mathrm{X}_{2} \\
& \begin{array}{lllll}
-0,085 & X_{3} & -0,054 & X_{4} & +0,274
\end{array} \\
& \mathrm{X}_{5}+0,165 \mathrm{X}_{6} \\
& \text { | e } \quad=2,234-0,038 \mathrm{Y}
\end{aligned}
$$

Tabel menggambarkan nilai koefisien parameternya bernilai negatif yaitu $-0,038$ dengan nilai signifikan 0,552 lebih besar dari $\alpha=0,05$. Kesimpulan dari pengujian residual ini menunjukkan bahawa variabel komitmen perofesional tidak dapat menjadi variabel pemoderasi bagi hubungan pengetahuan dewan tentang anggaran, personal background, poltical background, akuntabilitas publik, partisipasi masyarakat, dan transparansi kebijakan publik dengan kinerja DPRK dalam pengawasan keuangan daerah

\section{KESIMPULAN, KETERBATASAN DAN SARAN}

\section{Kesimpulan}

1. Secara simultan, penegatahuan dewan tentang anggaran, personal background, political background,akuntabilitas publik, partisipasi masayrakat, dan transparansi kebijakan publik memiliki pengaruh terhadap kinerja DPRK dalam pengawasan keuangan daerah.

Secara parsial, hasil pengujian menunjukkan pengetahuan dewan tentang anggaran, akuntabilitas publik, partisipasi masyarakat, dan transparansi kebijakan publikmemiliki pengaruh positif dan signifikan terhadap kinerja DPRK dalam pengawasan keuangan daerah. Variabel lainnya yaitupersonal background dan political background memiliki pengaruh negatif dan tidak berpengaruh signifikan terhadap kinerja DPRK dalam pengawasan keuangan daerah.

2. Komitmen professional yang merupakan varibel moderasi dalam penelitian ini tidak dapat menjadi variabel pemoderasi bagi hubungan penegatahuan dewan tentang anggaran, personal background, political background, akuntabilitas publik, partisipasi masayarakat, dan transparansi kebijakan publik dengan kinerja DPRK dalam pengawasan keuangan daerah pada DPRK Aceh Utara, karena meskipun memiliki parameter yang negatif namun nilai signifikannya lebih besar dari 0,05.

\section{Keterbatasan}

1. Hasil penelitian ini diperoleh dengan menggunakan instrumen kuesioner, dimana hasil yang didapatkan melalui kuisionerberdasarkan persepsi masingmasing jawaban responden. Hal tersebut mungkin akan memberikan masalah jika responden memiliki persepsi yang berbeda dengan realita yang ada dan mengandung unsur subjektif dan jawaban yang dibuat tidak jujur.

2. Berkaitan dengan poin 1 , responden pada penelitian inimerupakan anggota dewan yang berada di DPRK Kabupaten Aceh Utara yang sebagian besarberlatarbelakang pendidikan non ekonomi dengan tingkat pendidikan dan pengalaman di pemerintahan daerah yang rata-rata masih kurang, serta pengetahuan anggota dewan yang kurang memadai mengenai anggaran atataupun keuangan daerah sehingga agak sulit mencerna penjelasan, pertanyaan serta pernyataan yang berkaitan dengan keuangan daerah.

3. Penelitian ini tidak mempertimbangkan variabel-variabel lain yang mungkin dapat mempengaruhi kinerja DPRD dalam pengawasan keuangan daerah.

\section{Saran}

1. Peneliti mengharapkan pada peneliti selanjutnya juga dapat menambahkan metode wawancara dalam studi lapangan agar data yang diperoleh memiliki tingkat keakurasian yang tinggi dan lebih valid, karena peneliti dapat mengkomunikasikan item-item penting dari penelitian tersebut secara langsung kepada responden sehingga tidak salah persepsi dalam memberikan jawaban ataupun tidak sesuai realita. Pada variabel partisipasi masyarakat pada penelitian selanjutnya, diharapkan kuisioner diberikan kepada masyarakat, dengan demikian diharapkan tingkat analisis akan lebih akurat. 
2. Sebagai salah satu bahan kajian bagi anggotaDPRKAceh Utara agar seluruh anggota dewan lebih banyak lagi diberikan/diikutkan kedalam seminarseminar, pelatihan, dan diberikan pembekalan mengenai keuangan daerah guna meningkatkan kemampuan DPRK dalam pengawasan keuangan daerah dan lebih memamahami tugasnya sebagai wakil rakyat khusunya dalam pengawasan keuangan daerah.

3. Bagi peneliti berikutnya, diharapkan agar memperbanyak jumlah variabel independen, misalnya dengan mempertimbangkan variabel psychology dewan yang meliputi persepsi, sikap, kepribadian dan motivasi. Pada variabel personal background diharapkan dapat menambahkan indikator lainnya misalnya, mental fisik, latar belakang keluarga dan tingkat sosial. Pada variabel political background dapat menambahkan indikator budaya organisasi. Serta variabel dan indikator lainnya yang menjadi fenomena yang mampu mempengaruhi kinerja DPRD dalam pengawasan keuangan daerah.

\section{DAFTAR PUSTAKA}

Achmadi, Adib., Hendarto, Agung. dan Suhendra, Nizar. 2002. Good Governance dan Penguatan Institusi Daerah. Masyarakat Transparansi Indonesia, Jakarta.

Erlina dan Mulyani, Sri. 2007. Metodologi

Penelitian Bisnis: Untuk Akuntansi dan Manajemen. USU Press, Medan.

Fatma, Ade. 2012. Metode Penelitian Akuntansi dan Format Penulisan Tesis. USU Press, Medan.

Ghozali, Imam. 2006. Apikasi Analisis Multivariate dengan Program SPSS. Edisi Keempat.Badan Penerbitan Universitas Dipenogoro,

Semarang.

Ghozali, Imam. 2013. Apikasi Analisis Multivariate dengan Program SPSS. Edisi Ketujuh.Badan Penerbitan Universitas Dipenogoro,

Semarang.

Haryani, Rizki. 2011. Pengaruh Political Background dan Pengetahuan Dewan Tentang Anggaran Terhadap Kinerja DPRD dalam Pengawasan Keuangan Daerah $(A P B D)$ dengan Variabel Moderating
Transparansi Kebijakan Publik (Studi Kasus di DPRD Provinsi Sumatera Utara) [Tesis].Medan: Universitas Sumatera Utara, Sekolah Pascasarjana. Indriantoro dan Supomo. 1999. Metodologi

Penelitian Bisnis untuk Akuntansi danManajemen. BFF, Jogjakarta.

Jogiyanto. 2004.Metode Penelitian Bisnis. Andi, Jogjakarta.

Karianga, Hendra. 2001. Partisipasi Masyarakat dalam Pengelolaan Keuangan Daerah. PT. Alumni, Bandung.

Mardiasmo. 2002. Akuntansi SektorPublik. Andi, Yogyakarta.

Republik Indonesia, Peraturan Menteri Dalam Negeri No.13 Tahun 2006 tentang Pengelolaan Keuangan Daerah.

Republik Indonesia, Undang-Undang No.

11 Tahun 2006 tentang Pemerintah Aceh.

Republik Indonesia, Undang-Undang No.

23 Tahun 2014 tentang Pemerintahan Daerah.

Santoso, Sigih. 2002. Buku Latihan SPSS Statistik Parametrik. Gramedia, Jakarta.

Siregar, Liper. 2011. Pengaruh Akuntabilitas Publik, Transparansi Kebijakan Publik dan Pengawasan terhadap Pengelolaan APBD dengan Standar Akuntansi Pemerintahan Sebagai Variabel Moderator pada Pemerintahan Kota Pemantang Siantar [Tesis]. Medan: Universitas Sumatera Utara,sekolah Pascasarjana.

Trisnaningsih, Sri. 2008. Pengaruh Komitmen

Terhadap Kepuasan Auditor: Motivasi Sebagai Variabel Intervening (Studi Empiris Pada Kantor Akuntan Publik di Jawa Timur).Jurnal Riset Akuntansi Indonesia Vol.6(2).

Wardayani. 2010. Pengaruh Pengetahuan

Dewantentang Anggaran, Partisipasi Masyarakat dan Transparansi

Kebijakan Publik terhadap Kinerja DPRD dalam Pengawasan Keuangan Daerah dengan Komitmen Profesional

sebagai Variabel Pemoderasi [Tesis]. Medan: Universitas Sumatera Utara, Sekolah Pascasarjana.

Yudono, Bambang. (2002). Optimalisasi Peran DPRD Dalam Penyelenggaraan Pemerintah Daerah.http://www.bangda.depd gri.go.id/jurnal/jendela/ 
JURNAL AKUNTANSI DAN KEUANGAN

E-ISSN 2716-022X

Volume 8, Nomor 1, Februari 2020

P-ISSN 2301-4717

DOI: https://doi.org/10.29103/jak.v8i1.2276

p. $11-20$ 